\title{
Anxiety Effect in the Success Rate of Intrauterine Insemination (IUI) and In Vitro Fertilization (IVF)
}

\author{
Hanom H. Syam ${ }^{1,2}$, Tita H. Madjid ${ }^{1,2}$, Jusuf S. Effendi, ${ }^{1,2}$, Tono Djuwantono, ${ }^{1,2}$, \\ Wiryawan Permadi1 ${ }^{12}$, Zuhaira H. Fatma ${ }^{2}$ \\ ${ }^{1}$ Department of Obstetrics and Gynecology, Hasan Sadikin General Hospital, Bandung, Indonesia \\ ${ }^{2}$ Faculty of Medicine, Universitas Padjadjaran, Bandung, Indonesia \\ Email: hanomsyam@gmail.com
}

How to cite this paper: Syam, H.H., Madjid, T.H., Effendi, J.S., Djuwantono, T., Permadi, W. and Fatma, Z.H. (2017) Anxiety Effect in the Success Rate of Intrauterine Insemination (IUI) and In Vitro Fertilization (IVF). Open Access Library Journal, 4: e3691. https://doi.org/10.4236/oalib.1103691

Received: May 26, 2017

Accepted: June 20, 2017

Published: June 23, 2017

Copyright $\odot 2017$ by authors and Open Access Library Inc.

This work is licensed under the Creative Commons Attribution International License (CC BY 4.0).

http://creativecommons.org/licenses/by/4.0/

\begin{abstract}
Background: Infertility has a tendency to become potential physical and emotional stressors. The current progressive advances in fertility technology have encouraged more infertile couples to seek for the cause of infertility and take measures to improve their fertility. It is not uncommon that these couples experience emotional distress when they are undergoing fertility treatments. Although it is controversial, some experts argue that this emotional distress affects the success of fertility programs, such as intrauterine insemination and in vitro fertilization programs. Objective: The aim of the study was to investigate the relationship between successful pregnancy and anxiety in patients undergoing intrauterine insemination (IUI) and in vitro fertilization (IVF) programs. Material and method: A total of 39 patients undergoing intrauterine insemination and in vitro fertilization program in Aster clinic of Dr. Hasan Sadikin General Hospital during period of September-November 2016 were measured for their anxiety level using Zung SelfRating Anxiety Scale. The results were then categorized as not anxious (score of 20 - 44) and anxious (45 - 80). Data were then compared against successful pregnancy after each program. Results: Of 39 patients, 23 underwent IUI and 16 underwent IVF. In the IUI group, 10 patients were not anxious (43.48\%) and 13 people were anxious (56.52\%) while in the IVF group 9 were not anxious $(56.25 \%)$ and 7 were anxious (43.75\%). Three patients (18\%) who successfully conceived in the insemination program were those who were not anxious. Meanwhile, in the IVF group 3 patients (18.8\%) also got pregnant with 2 of them were not anxious and 1 was anxious. A statistical calculation was performed using Fisher test, resulting in $\mathrm{p}=0.068$ and $\mathrm{p}=1.000$ for IUI and IVF, respectively. Conclusion: There is no significant correlation between the success of the fertility program and anxiety in patients undergoing IUI and
\end{abstract}


IVF programs.

\section{Subject Areas}

Obstetrics and Gynecology

\section{Keywords}

Anxiety, Intrauterine Insemination, In Vitro Fertilization, Pregnancy Rate

\section{Introduction}

The inability to have children after being married for more than 1 year without using any contraception is commonly known as infertility. Infertility has increased over the past few decades and has become a social and challenging problem for healthcare providers around the world. More and more couples are coming to fertility centers because of difficulties to get pregnant. Advances in medical approaches have enabled us to continue looking for the causes of infertility and perform actions to improve fertility. As soon as the cause is known, the patient undergoes therapies to conceive. Treatments of infertility are divided into drugs, insemination and assisted reproductive technology (ART) [1]. It is not uncommon that the couple undergoing infertility therapies becomes susceptible to the problem of anxiety and stress associated with the experience of their infertility and the preparation of the infertility therapy [2], lack of enjoyment during intercourse, lack of respect for sexual intercourse, and even avoiding intercourse [3]. In fact, sometimes it is these problems that led to infertility as referred to by some authors as the "psychogenic infertility" that includes factors such as personality, family relationships, sexual disorders, guilty feelings, the urgent desire to have a baby, or fear of labor, which are all known to lower fertility [4]. Anxiety is the topic discussed in this study that is the most frequently found mental disorders [5]. The anxiety trait refers to individuals who tend to respond to stressful situations with increased anxiety. The state of anxiety is a subjective emotional condition that is temporarily or momentarily experienced by individuals due to tensions and anxiety, triggering the autonomic nervous system activities [6].

The assisted reproductive technology (ART) also contains risk factors that can cause behavioral and psychological changes for those who receive it. There are 3 main issues that are routinely experienced by patients during the couple's preparation both before and during the therapy. First is the thought of the possibility of permanent infertility or losing hope of having children. Second is the expectation towards the outcome of therapy itself. The third is during the procedure, or what is referred to as procedural or situational distress in which anxiety may arise from fear of daily hormone injections or pain during oocyte retrieval or emotionally tense moment during the embryo transfer. In a recent study of couples undergoing ART, it is evident that these couples tend to have a high lev- 
el of anxiety [7] [8] [9].

The importance of finding out the factors that can affect the success of fertility therapy is also a priority in the development of today's assisted reproductive technology. Attention is more focused on the negative consequences on the mental state as the consequences of infertility and the procedure even tends to be invasive. One of the issues examined in this type of research is anxiety. The effect of anxiety is one of the psychological factors that have been studied before. Frustration, aggression, depression, and anxiety are known to affect the success of pregnancy. Previous data on these effects conclude that high level of anxiety affects the number of cycles of insemination that must be endured by the patients to get pregnant and also the incidence of spontaneous abortion that occurs early in pregnancy, which is more probable in anxious pregnant women than in other pregnant women [10]. A study by Britt, et al. showed that a higher level of anxiety was more frequently found in infertile couples compared to other couples. They also concluded that during fertility therapies, many couples are relatively stressed [11].

Intrauterine insemination, a therapeutic process by placing washed spermatozoa transcervically into the uterine cavity becomes the first choice of infertile couples with mild causes, especially those cases with weak sperms, anovulation, endometriosis with at least 1 patent tube, and unexplained infertility. The reason why this procedure and ovulation induction is selected as the first choice includes the practicality because it is simple, low cost, and hardly leads to serious complications [12].

Assisted reproductive technologies such as in vitro fertilization and intracytoplasmic sperm injection are more complex and may lead to psychological impacts. In each cycle of in vitro fertilization, 9 to 12 days after injection are usually required stimulate oocyte production, oocyte removal via transvaginal ultrasonography, fertilization of the oocyte with partner sperm in the laboratory, and transfer the resulting embryo into the uterus. Then the couple has to wait 2 to 3 weeks to find out whether implantation or pregnancy occurs. The duration of each stage of in vitro fertilization can create psychological effects on the patient. Turner et al., when researching 44 women, found an increase of anxiety of almost all women underwent in vitro fertilization therapy based on the psychometric results. He also found that women who initially had a low level of anxiety prior to oocyte retrieval have a higher rate of successful pregnancy [13]. On the contrary, some studies fail to prove the connection between anxiety and the success of fertility treatment [6] [14], including a meta-analysis of 31 prospective study. In this study, one of the findings is that no association is found between anxiety disorders and the therapeutic efficacy of the assisted reproductive therapy (ART) [15].

This study aimed to determine the relationship between the success of therapy and anxiety in patients undergoing intrauterine insemination (IUI) and in vitro fertilization (IVF) programs. These results of this study can be used as scientific evidence for the development of therapeutic and psychological therapies in im- 
proving the success of reproductive technology in infertile women.

\section{Methods}

This study measured the level of anxiety in every patient receiving fertility treatment in Aster Fertility Clinic of Dr. Hasan Sadikin General Hospital Bandung during period of September-November 2016. The subjects of this study included women who underwent fertility therapies and had not declared to be pregnant. The inclusion criteria were patients/participants underwent intrauterine insemination and IVF programs that can be contacted either directly or via telephone. The exclusion criteria were patients/participants underwent other fertility programs in addition to intrauterine insemination and in vitro fertilization. Based on categorical comparative analysis test, minimal 15 samples are needed. Variables used in this study were patient characteristics and the effect of anxiety on the success of intrauterine insemination and IVF.

The state of anxiety was identified using Zung Self-Rating Anxiety Scale [16] which had been translated into Indonesian. The questionnaire containing 20 questions, with a range of scores of 1 to 4 per question, the resulting scores were interpreted as follows: 20 to 44 as normal/no anxiety, $45-59$ as mild to moderate anxiety level, 60 - 74 as severe anxiety level, and 75 - 80 as extreme anxiety level. Patients were then interviewed after the therapy. In IUI patients, the pregnancy check was performed starting 2 weeks after insemination. In IVF patients, a pregnancy check is performed during the follow up visit to the clinic. The results were processed using a table by counting the number and percentage. Data were analyzed using Microsoft Excel and SPSS. The p value of $<0.05$ was considered statistically significant.

This study was approved by the hospital ethics committee. Any information collected from patients has been and will remain confidential. All the patients have agreed to sign the informed consent and have a whole understanding of this study.

\section{Result}

In this study, 39 subjects were recruited. The variables used are patient characteristics and effect of anxiety to the success of pregnancy. The subjects were divided into 2 separate groups: subjects underwent intrauterine insemination and subjects underwent in vitro fertilization.

The characteristics of intrauterine insemination and in vitro fertilization patients are presented in Table 1 based on age, education, wife's occupation, husband's occupation, number of children, and infertility status. The age composition of patients underwent insemination were 14 patients were 35 years old (60.8\%); 6 patients were 35 - 40 years old $(26.1 \%)$ and 3 patients were 40 years old and above (13.0\%). Meanwhile, the age composition for the age criteria for fertilization program patient is as follows: 7 patients were 35 years old (43.7\%), 9 patients were 35 - 40 years old (56.3\%), and none was over the age of 40 years old. Apparently the insemination program tends to be chosen by 
Table 1. Characteristics of intrauterine insemination and in vitro fertilization patients in Aster Clinic of Dr. Hasan Sadikin General hospital Bandung.

\begin{tabular}{|c|c|c|}
\hline \multirow{2}{*}{ Characteristics } & \multicolumn{2}{|c|}{ Group } \\
\hline & Insemination $\mathrm{n}(\%)$ & In Vitro Fertilization $\mathrm{n}(\%)$ \\
\hline \multicolumn{3}{|l|}{ Age } \\
\hline$<35$ yrs. & $14(60.8)$ & $7(43.7)$ \\
\hline $35-40$ yrs. & $6(26.1)$ & $9(56.3)$ \\
\hline$>40$ yrs. & $3(13.0)$ & $0(0)$ \\
\hline \multicolumn{3}{|l|}{ Education } \\
\hline Junior High School & $0(0)$ & $1(6.2)$ \\
\hline Senior High School & $8(34.8)$ & $4(25)$ \\
\hline D3 & $5(21.7)$ & $1(6.2)$ \\
\hline Bachelor & $7(30.4)$ & $8(50.0)$ \\
\hline Master & $3(13.0)$ & $2(12.5)$ \\
\hline \multicolumn{3}{|l|}{ Wife's Occupation } \\
\hline Civil Servant & $4(17.4)$ & $4(25.0)$ \\
\hline Private Employee & $7(30.4)$ & $2(12.5)$ \\
\hline Housewife & $7(30.4)$ & $4(25.0)$ \\
\hline Others & $5(21.7)$ & $6(37.5)$ \\
\hline \multicolumn{3}{|l|}{ Husband's Occupation } \\
\hline Civil Servant & $5(21.7)$ & $2(12.5)$ \\
\hline Private Employee & $8(34.8)$ & $6(37.5)$ \\
\hline Others & $10(43.4)$ & $8(50.0)$ \\
\hline \multicolumn{3}{|l|}{ Infertility Status } \\
\hline Primary & $23(100)$ & $14(87.5)$ \\
\hline Secondary & $0(0)$ & $2(12.5)$ \\
\hline
\end{tabular}

younger infertile couples (under 35 years) whereas in in vitro fertilization was mostly chosen by those who were 35 - 40 years of age.

The data on educational level of the intrauterine insemination patients presented that 8 patients graduated from senior high school (34.8\%), 5 graduated from D3 program (21.7\%), 7 were bachelor program graduates $(30.4 \%)$, and 3 had a master degree (13.0\%). Meanwhile, the educational level of the in vitro fertilization patients showed that 1 patient graduated junior high school (6.2\%), 4 graduated from senior high school (25.0\%), 1 graduated from D3 program (6.2\%), 8 graduated from bachelor program (50.0\%) and 2 had a master degree (12.5\%). It seems that the majority patients undergoing intrauterine insemination programs were senior high school graduate whereas most of the in vitro fertilization patients have graduated from a bachelor program. This level of education may have an effect on the selection and decision making on the choice of fertility therapy chosen by the couple.

In terms the job composition of the wives who underwent the intrauterine insemination program, the data show that 5 were civil servants $(21.7 \%), 7$ were 
private employees $(30.4 \%), 7$ were housewives $(30.4 \%)$, and 5 had other jobs (21.7\%). Meanwhile, for the in vitro fertilization program, the job composition presented that 4 were civil servants (25.0\%), 2 were private employees $(12.5 \%), 4$ were housewives (25.0\%), and 6 had other jobs (37.5\%). As for the husbands of patients who underwent intrauterine insemination program, 5 were civil servants $(21.7 \%), 8$ were private employees (34.8\%), and 10 had other jobs $(34.8 \%)$. For the husbands of the in vitro fertilization patients, 2 were civil servants (12.5\%), 6 were private employees (37.5\%), and 8 had other jobs (50.0\%).

The infertility status of all intrauterine insemination patients was primary infertility ( $\mathrm{n}=23,100 \%$ ) while 14 of the in vitro fertilization patients experienced primary infertility $(87.5 \%)$ with 2 had secondary infertility $(12.5 \%)$.

Table 2 describes anxiety in each type of fertility therapy. In intrauterine insemination, the majority of patients experienced anxiety (56.52\%), whereas in in vitro fertilization, the majority of patients did not experience anxiety (56.25\%). There is no significant difference in terms of anxiety by type of fertility therapy $(\mathrm{p}>0.05)$

In Table 3, the effect of anxiety on successful pregnancy in intrauterine insemination patients (Table 3 ) shows that there is no significant difference in terms of the relationship between anxiety status and the insemination therapy outcome $(\mathrm{p}=0.068)$.

In Table 4, the effect of anxiety on successful pregnancy in in vitro fertilization patients shows that there is no significant difference in terms of the relationship between anxiety status and the in vitro fertilization program outcome $(\mathrm{p}=1.00)$.

Table 2. Anxiety by type of fertility therapy in Aster Clinic of Dr. Hasan Sadikin General hospital Bandung.

\begin{tabular}{ccccc}
\hline Program & $\begin{array}{c}\text { Normal/without } \\
\text { anxiety } \mathbf{n}(\%)\end{array}$ & $\begin{array}{c}\text { With anxiety } \\
\mathbf{n}(\%)\end{array}$ & Total & \\
\hline $\begin{array}{c}\text { Intrauterine } \\
\text { Insemination }\end{array}$ & $10(43.48)$ & $13(56.52)$ & $23(100)$ & Fisher Exact \\
$\begin{array}{c}\text { In Vitro } \\
\text { Fertilization } \\
\text { Total }\end{array}$ & $9(56.25)$ & $7(43.75)$ & $16(100)$ & $\begin{array}{c}\text { Test }=0.52 \\
\mathrm{p}>0.05\end{array}$ \\
\hline
\end{tabular}

Table 3. Effect of anxiety on the success of therapy in patients participating in intrauterine insemination.

\begin{tabular}{|c|c|c|c|c|c|}
\hline & & \multicolumn{2}{|c|}{ Insemination Therapy Outcome } & \multirow[t]{2}{*}{ Total } & \multirow[t]{2}{*}{$P$ value } \\
\hline & & Pregnant n (\%) & Not Pregnant n (\%) & & \\
\hline \multirow[t]{3}{*}{$\begin{array}{c}\text { Anxiety } \\
\text { Status }\end{array}$} & Normal & $3(30)$ & $7(70.0)$ & $10(100.0)$ & 0.068 \\
\hline & Anxious & $0(0.0)$ & $13(100.0)$ & $13(100.0)$ & \\
\hline & Total & $3(18.0)$ & $20(87.0)$ & $23(100.0)$ & \\
\hline
\end{tabular}


Table 4. Effect of anxiety on the success of therapy in patients participating in in vitro fertilization program.

\begin{tabular}{|c|c|c|c|c|c|}
\hline & & \multicolumn{2}{|c|}{$\begin{array}{c}\text { In Vitro Fertilization Therapy } \\
\text { Outcome }\end{array}$} & \multirow[t]{2}{*}{ Total } & \multirow[t]{2}{*}{$P$ value } \\
\hline & & Pregnant n (\%) & Not Pregnant n (\%) & & \\
\hline \multirow[t]{3}{*}{$\begin{array}{l}\text { Anxiety } \\
\text { Status }\end{array}$} & Normal & $2(22.2)$ & $7(77.8)$ & $9(100.0)$ & 1.000 \\
\hline & Anxious & $1(14.3)$ & $6(85.7)$ & $7(100.0)$ & \\
\hline & Total & $3(36.5)$ & $13(81.3)$ & $16(100.0)$ & \\
\hline
\end{tabular}

\section{Discussion}

This study correlates the successful outcome in the form of pregnancy with the presence of anxiety in patients' undergoing intrauterine insemination and in vitro fertilization programs. From the results, it is evident that there is no significant association between the success of therapy and anxiety in patients undergoing intrauterine insemination and in vitro fertilization programs. Some studies from other researchers also do not see this relationship. A meta-analysis study by Boivin et al. that compared 14 studies with 3584 infertile women undergoing infertility treatment. Presented that anxiety or depression (emotional distress) is not the cause of the failure of fertility treatment [17].

Another study conducted by Hashemi et al. evaluated both the effect of state of anxiety and anxiety trait on the success rate of ART. At the end of his research, Hashemi et al. did not find any effect of state of anxiety and anxiety trait in pregnancy success [6].

Another study that supports the above research that there is no significant effect of ART therapy and the prevalence of anxiety disorders is a study on a woman group in Denmark that includes 98,320 women that shows no relationship in the success of the infertility treatment between those with and without the risk of anxiety [18]. A study by Milad et al. and Harlow et al. stated that both pregnant and non-pregnant groups have a similar anxiety levels. The high anxiety and stress also does not predict adverse pregnancy outcomes [19] [20]. It has been reported also that infertility patients undergoing fertility treatment sometimes suppress their feelings of stress and anxiety because they want to show to the clinic that they function well, both socially and psycho- logically [21].

There are several studies that show the effect of anxiety on the pregnancy success in patients undergoing intrauterine insemination and ART. Kokanali et al. concluded that the state of anxiety affects the success of intrauterine insemination, and they suggested the need for counseling program in intrauterine insemination therapy [22]. In another study performed by Matthiesen et al. a significant correlation was found between stress and distress and the reduced success of becoming pregnant in ART program [15]. Some researchers even learned the effect in the body when a woman experienced anxiety and its effect on the 
therapy. Some studies found that existing anxiety and high cortisol level before oocyte retrival (OR) and embryo transfer (ET) will lead to low number of successful pregnancy [23].

This study did not find a significant effect of anxiety on the success of getting pregnant in patients undergoing intrauterine insemination and in vitro fertilization programs. This may be due to the fact that Aster Fertility Clinic of Dr. Hasan Sadikin General Hospital Bandung, routinely conducts infertility classes for prospective participants of the fertility program so they know the steps of the therapy and issues regarding infertility. Patients also had discussion, sharing experience from those who have participated in a fertility program before. So it is likely that many potential patients of the fertility program have a relative mental readiness before undergoing the fertility therapy. This should be examined further in further research.

This study has a limitation in addition to the limited sample, which is the presence of some confounding factors that may affect the success of the program such as caffeine and alcohol intake and psychosocial factors such as the stress level of the husband. Biochemical markers of stress like cortisol were also not measured in this study. Hence, future studies are expected to be able to investigate the relationship between anxiety and the above risk factors that may affect patients during data collection of this study.

\section{Conclusion}

There is no significant relationship identified in this study between the success of getting pregnant and the presence of anxiety in patients who undergo intrauterine insemination and in vitro fertilization programs.

\section{References}

[1] Sharma, S., Khinchi, M.P., Sharma, N., Agrawal, D. and Gupta, M.K. (2011) Female Infertility: An Overview. International Journal of Pharmaceutical Sciences and Research, 2, 1-12.

[2] Peterson, B.D., Newton, C.R. and Feingold, T. (2007) Anxiety and Sexual Stress in Men and Women Undergoing Infertility Treatment. Fertility and Sterility, 88, 911914.

[3] Newton, C.R., Sherrard, W. and Glavac, I. (1999) The Fertility Problem Inventory: Measuring Perceived Infertility-Related Stress. Fertility and Sterility, 72, 54-62.

[4] Podolska, M.Z. and Bidzan, M. (2011) Infertility as a Psychological Problem. Ginekologia Polska, 82, 44-49.

[5] Kessler, R.C., Chiu, W.T., Demler, O., Merikangas, K.R. and Walters, E.E. (2005) Prevalence, Severity, and Comorbidity of 12-Month DSM-IV Disorders in the National Comorbidity Survey Replication. Archives of General Psychiatry, 62, 617-627. https://doi.org/10.1001/archpsyc.62.6.617

[6] Hashemi, S., Simbar, M., Ramezani-Tehrani, F., Shams, J. and Majd, H.A. (2012) Anxiety and Success of In Vitro Fertilization. European Journal of Obstetrics \& Gynecology and Reproductive Biology, 164, 60-64. https://doi.org/10.1016/j.ejogrb.2012.05.032

[7] Chiaffarino, F., Baldini, M.P., Scarduelli, C., Bommarito, F., Ambrosio, S., D’Orsi, 
C., et al. (2011) Prevalence and Incidence of Depressive and Anxious Symptoms in Couples Undergoing Assisted Reproductive Treatment in an Italian Infertility Department. European Journal of Obstetrics \& Gynecology and Reproductive Biology, 158, 235-241. https://doi.org/10.1016/j.ejogrb.2011.04.032

[8] Volgsten, H., SkoogSvanberg, A., Ekselius, L., Lundkvist, O. and SundstromPoromaa, I. (2008) Prevalence of Psychiatric Disorders in Infertile Women and Men Undergoing In Vitro Fertilization Treatment. Human Reproduction, 23, 2056-2063. https://doi.org/10.1093/humrep/den154

[9] McMahon, C.A., Ungerer, J.A., Beaurepaire, J., Tennant, C. and Saunders, D. (1997) Anxiety during Pregnancy and Fetal Attachment after In-Vitro Fertilization Conception. Human Reproduction, 12, 176-182.

https://doi.org/10.1093/humrep/12.1.176

[10] Gray, J.D., Tupper, C. and Rowse, J.A. (1959) The Problem of Spontaneous Abortion. VII. Prematurity and Spontaneous Abortion. American Journal of Obstetrics \& Gynecology, 78, 325-332. https://doi.org/10.1016/0002-9378(59)90182-6

[11] Britt, D.W., Risinger, S.T., Mans, M. and Evans, M.I. (2003) Anxiety among Women Who Have Undergone Fertility Therapy and Who Are Considering Multifetal Pregnancy Reduction: Trends and Implications. The Journal of Maternal-Fetal \& Neonatal Medicine, 13, 271-278. https://doi.org/10.1080/jmf.13.4.271.278

[12] Veltman-Verhulst, S.M., Hughes, E., Ayeleke, R.O. and Cohlen, B.J. (2016) Intra-Uterine Insemination for Unexplained Subfertility. The Cochrane Database of Systematic Reviews, No. 2, Article No. CD001838. https://doi.org/10.1002/14651858.cd001838.pub5

[13] Turner, K., Reynolds-May, M.F., Zitek, E.M., Tisdale, R.L., Carlisle, A.B. and Westphal, L.M. (2013) Stress and Anxiety Scores in First and Repeat IVF Cycles: A Pilot Study. PLoS ONE, 8, e63743. https://doi.org/10.1371/journal.pone.0063743

[14] Pasch, L.A., Gregorich, S.E., Katz, P.K., Millstein, S.G., Nachtigall, R.D., Bleil, M.E., et al. (2012) Psychological Distress and In Vitro Fertilization Outcome. Fertility and Sterility, 98, 459-464. https://doi.org/10.1016/j.fertnstert.2012.05.023

[15] Matthiesen, S.M., Frederiksen, Y., Ingerslev, H.J. and Zachariae, R. (2011) Stress, Distress and Outcome of Assisted Reproductive Technology (ART): A Meta-Analysis. Human Reproduction, 26, 2763-2776. https://doi.org/10.1093/humrep/der246

[16] Zung, W.W. (1971) A Rating Instrument for Anxiety Disorders. Psychosomatics, 12, 371-379. https://doi.org/10.1016/S0033-3182(71)71479-0

[17] Boivin, J., Griffiths, E. and Venetis, C.A. (2011) Emotional Distress in Infertile Women and Failure of Assisted Reproductive Technologies: Meta-Analysis of Prospective Psychosocial Studies. BMJ, 342, d223. https://doi.org/10.1136/bmj.d223

[18] Baldur-Felskov, B., Kjaer, S.K., Albieri, V., Steding-Jessen, M., Kjaer, T., Johansen, C., et al. (2013) Psychiatric Disorders in Women with Fertility Problems: Results from a Large Danish Register-Based Cohort Study. Human Reproduction, 28, 683690. https://doi.org/10.1093/humrep/des422

[19] Milad, M.P., Klock, S.C., Moses, S. and Chatterton, R. (1998) Stress and Anxiety Do Not Result in Pregnancy Wastage. Human Reproduction, 13, 2296-2300. https://doi.org/10.1093/humrep/13.8.2296

[20] Harlow, C.R., Fahy, U.M., Talbot, W.M., Wardle, P.G. and Hull, M.G. (1996) Stress and Stress-Related Hormones during In-vitro Fertilization Treatment. Human Reproduction, 11, 274-279. https://doi.org/10.1093/HUMREP/11.2.274

[21] Demyttenaere, K., Bonte, L., Gheldof, M., Vervaeke, M., Meuleman, C., Vanderschu-erem, D., et al. (1998) Coping Style and Depression Level Influence Outcome 
in In Vitro Fertilization. Fertility and Sterility, 69, 1026-1033.

https://doi.org/10.1016/s0015-0282(98)00089-2

[22] Kokonali, D., Kokonali, M.K., Eroglu, E. and Yilmaz, N. (2015) Is Anxiety an Effective Factor on the Success of Ovulation Induction/Intrauterine Insemination Cycle? Journal of Clinical and Analytical Medicine, 6, 770-773.

[23] Smeenk, J.M., Verhaak, C.M., Eugster, A., van Minnen, A., Zielhuis, G.A. and Braat, D.D. (2001) The Effect of Anxiety and Depression on the Outcome of In-Vitro Fertilization. Human Reproduction, 16, 1420-1423.

https://doi.org/10.1093/humrep/16.7.1420

Submit or recommend next manuscript to OALib Journal and we will provide best service for you:

- Publication frequency: Monthly

- 9 subject areas of science, technology and medicine

- Fair and rigorous peer-review system

- Fast publication process

- Article promotion in various social networking sites (LinkedIn, Facebook, Twitter, etc.)

- Maximum dissemination of your research work

Submit Your Paper Online: Click Here to Submit

Or Contact service@oalib.com 